\title{
Experimental Study on Anchorage Performance of Steel Bars with FRP Confined Rings
}

\author{
Qiao Jin ${ }^{1, \mathrm{a}}$, Jinglong $\mathrm{Li}^{1}$,Meng $\mathrm{Gao}^{2}$,Xuebin $\mathrm{Wen}^{3}$ and Zeming Zhao ${ }^{1}$ \\ ${ }^{1}$ School of Civil Engineering, Shenyang Jianzhu University, 110168 Shenyang, China \\ ${ }^{2}$ Chengdu benchmark Building Design Co. LTD, Chengdu, 610000, China \\ ${ }^{3}$ Zhong Tian Construction Group, Huzhou, 313000, China
}

\begin{abstract}
In order to study the performance of reinforcement anchorage connection with FRP restrained ring, static tensile tests were carried out on 66 specimens, The main parameters considered in the test such as the diameter of steel bars, the diameter and thickness of the restraint ring, the strength of concrete and the length of anchorage. The result shows that the anchorage performance of the steel bar can still be guaranteed even if the anchorage length reaches $0.8 l_{a}$, There is no slip and local destruction phenomenon between FRP restraint ring and internal grouting material and peripheral concrete. The study conclusions also indirectly prove that the proposed technique is a reinforcement connection method for fabricated concrete structures with many good performances including the reliable performance, simple construction process and good economic benefit, which is suitable for construction industrialization of prefabricated reinforced concrete structures..
\end{abstract}

\section{Introduction}

In today's international architecture field, especially in today's advocating green environmental protection concept of harmonious society development, our country vigorously develops the housing industrialization. The housing industrialization is a kind of residential construction method that produces prefabricated components at the factory and assembles, connects, and installs molding at the construction site. The key technology of housing industrialization is whether the assembly and connection of prefabricated components are reliable. Domestic and foreign scholars have conducted relevant study on this topic: For example, Jiang hongbin and zhang hailong et al carried out the experimental research on the anchorage performance of precast concrete structure with inserted prehole grouting reinforcement. The main influence parameters such as the diameter of reinforcement, the strength of concrete and the length of anchorage are considered ${ }^{[1-2]}$. Zhang Xinghu et al carried out an experimental study on the seismic behavior of precast columns connected with sleeve slurry anchor, and verified the reliability of its connection $\operatorname{mode}^{[3]}$. Aizat et al carried out an experimental study on the influence of the transverse reinforcement of precast concrete structure grouting connection sleeve $\mathrm{e}^{[4]}$.

On this basis, in this paper, a new connection way of reinforcement is put forward, which is "reinforced bar lap connection with FRP restraining rings". In order to understand the performance of reinforcement connection in this way, we should first determine the anchorage performance of the steel bar in this way. This paper mainly carries on the steel bar anchorage test research of this technology. The main parameters in the test are the diameter of the steel bar, the diameter of the restraint ring, the thickness of the restraint ring, the strength of the concrete and the anchorage length. The basic anchorage performance of the new connection method is studied through experiments, so as to determine the anchorage length suitable for the connection method of the reinforcement.

\section{Experimental research}

\subsection{Specimen design}

Fig. 1 is for each dimension of grouting reinforcement test specimen with FRP restraint ring. The specimens uniformly used $200 \mathrm{~mm} * 200 \mathrm{~mm}$ concrete sections. The anchorage length of the three kinds of steel bars is 1 steel bars, 0.9 times the basic anchorage length and 0.8 times the basic anchorage length. The type of steel bar is HRB400, and its diameter uses five kinds of $12 \mathrm{~mm}$, $14 \mathrm{~mm}, 16 \mathrm{~mm}, 20 \mathrm{~mm}$ and $22 \mathrm{~mm}$ respectively. The length of the steel bar at the loading end is $630 \mathrm{~mm}$ and the length of the free end is $30 \mathrm{~mm}$. The strength of concrete is considered as two kinds of C30 and C40. Using a custom FRP constraint ring as shown in Figure 2, The height of the inner rib and the outer rib of the FRP restraint ring is $3 \mathrm{~mm}$, the inclination angle is 15 degrees, the width is $20 \mathrm{~mm}$, the inner diameter is $75 \mathrm{~mm}$ and $80 \mathrm{~mm}$ respectively, and the wall thickness is 3 and $4 \mathrm{~mm}$

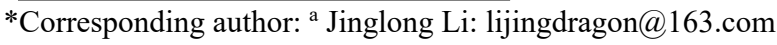


respectively. Considering these technical parameters, a total of 66 sets of test pieces were designed.

In addition, in order to expand the application scope of reinforcing bar connection technology with FRP confinement ring, the test also added the anchorage test of ribbed reinforcing bar with the strength of HRB400, diameter of $20 \mathrm{~mm}$ and $22 \mathrm{~mm}$, with 6 groups of specimens, each of which is 2 , the strength of concrete is $\mathrm{C} 40$, and the concrete number is shown in Table 1.

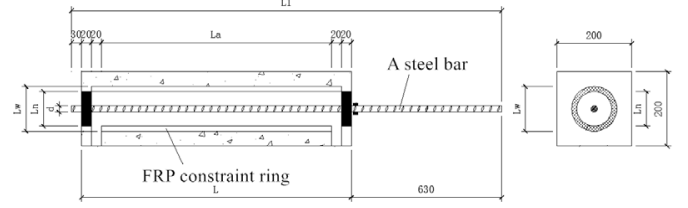

Fig. 1 Schematic diagram of reinforced bar anchorage

Table 1 Size table of anchorage test specimens（Unit: $\mathrm{mm}$ )

\begin{tabular}{|c|c|c|c|c|c|c|c|c|}
\hline HRB400 & number & $\begin{array}{l}\text { Diameter } \\
\text { of steel } \\
\text { bar }\end{array}$ & Anchorage length & $\begin{array}{c}\text { Specimen } \\
\text { length } \\
L\end{array}$ & $\begin{array}{c}\text { Length of } \\
\text { steel bar } \\
L_{1}\end{array}$ & $\begin{array}{l}\text { Wall thickness } \\
\text { of FRP } \\
\text { confinement } \\
\text { ring }\end{array}$ & $\begin{array}{c}\text { Inner } \\
\text { diameter of } \\
\text { FRP } \\
\text { constraint } \\
\text { ring } L_{n}\end{array}$ & $\begin{array}{c}\text { Number } \\
\text { of } \\
\text { specimens }\end{array}$ \\
\hline \multirow{3}{*}{$\mathrm{C} 40$} & U1 & \multirow{3}{*}{20} & $l_{a}=700$ & 780 & 1440 & 4 & 80 & 2 \\
\hline & $\mathrm{U} 2$ & & $0.9 l_{a}=630$ & 710 & 1370 & 4 & 75 & 2 \\
\hline & U3 & & $0.8 l_{a}=560$ & 640 & 1300 & 3 & 75 & 2 \\
\hline \multirow{3}{*}{ C40 } & V1 & \multirow{3}{*}{22} & $l_{a}=770$ & 850 & 1510 & 4 & 80 & 2 \\
\hline & V2 & & $0.9 l_{a}=693$ & 793 & 1453 & 4 & 75 & 2 \\
\hline & V3 & & $0.8 l_{a}=616$ & 696 & 1356 & 3 & 75 & 2 \\
\hline
\end{tabular}

\subsection{Material properties}

While pouring the specimen, the concrete cube blocks of $150 \mathrm{~mm}^{*} 150 \mathrm{~mm} * 150 \mathrm{~mm}$ reserved for each test piece are maintained at the same condition with the specimen. The mechanical properties of the concrete cube test block are measured at the same time in the test piece test. The compressive strength of C30 concrete is $31.5 \mathrm{MPa}$, and the compressive strength of C40 concrete is $41.9 \mathrm{MPa}$. We made 3 sizes of $40 \mathrm{~mm}^{*}$ $40 \mathrm{~mm}^{*} 160 \mathrm{~mm}$ grouting material prism. With the loading rate of $(2400+200) \mathrm{N} / \mathrm{s}$, the compressive strength of grouting material is $81.4 \mathrm{MPa}$. The tensile strength of FRP restrained ring is $100 \mathrm{MPa}$, the circumferential stiffness is $350 \mathrm{MPa}$, and the elongation at break is $3.5 \%$. The strength grade of the connecting bar is HRB400, and the material property of the reinforcement is obtained according to the room temperature test method, as shown in Table 1.

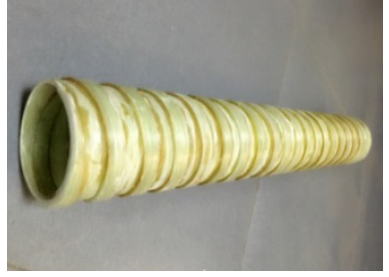

Fig. 2 FRP constraint ring
Table 2 Steel bar material property

\begin{tabular}{|c|c|c|}
\hline $\begin{array}{c}\text { Diameter of steel } \\
\text { bar } / \mathrm{mm}\end{array}$ & $\begin{array}{c}\text { Yield strength } \\
/ \mathrm{MPa}\end{array}$ & $\begin{array}{c}\text { ultimate strength } \\
/ \mathrm{MPa}\end{array}$ \\
\hline 12 & 449 & 610 \\
\hline 14 & 410 & 615 \\
\hline 16 & 435 & 605 \\
\hline 20 & 447 & 605 \\
\hline 22 & 455 & 625 \\
\hline
\end{tabular}

\subsection{Test device}

The test loading device diagram is shown in Figure 3. In this test, the manual hydraulic jack is used to carry out the unidirectional continuous loading. The loading speed is controlled according to the standard. The steel bar in the test specimen is yielded so that the fracture is broken. Through the hydraulic sensor, displacement gauge and strain gauge, we get the added load value, the elongation at the loading end, the free end slip and the reinforcement strain. 


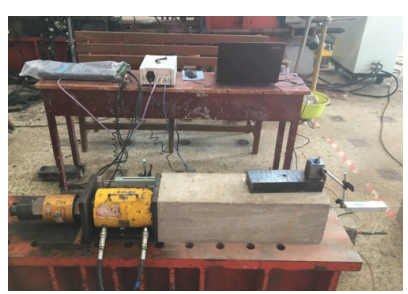

Fig. 3 Test apparatus

\subsection{Content and method of measurement}

The process of the test can be summed up as: First, strain gauges are placed near the ends of the concrete members at the loading ends of the reinforcement. Then, the anchorage performance test of the steel bar is carried out. In the static tensile process, the strain of the reinforcement is read out by the data acquisition board under the increasing load. The load is obtained by the tension sensor, and the slip of the steel bar can be measured at both ends of the steel bar. The test items should include the following contents: the slip value of the free end bar of the specimen and the elongation at the loading end, the value of the yield load of the steel bar and the limit load value, and the strain of the steel bar collected by the data acquisition board.

\section{Experimental results and analysis}

\subsection{Destruction form}

During the test, the test phenomena of the 66 groups of test components were all broken off at the end of the load. During the whole loading process, there is no slip and partial damage between the FRP restraint ring with the inner grouting material and the surrounding concrete. Figure 4 summarizes the cross-section of the test specimen.

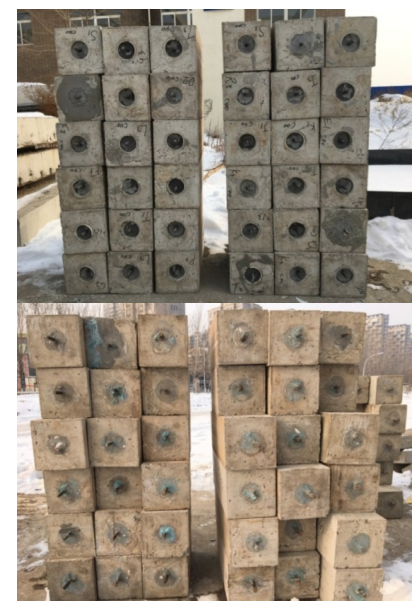

Fig. 4 Loading and Free end reinforcement
Figure 5 shows the U3 specimen after the steel bar anchorage test, open the interior of the specimen displayed along the longitudinal direction. As can be seen from figure 6 , in the whole process of the test, the FRP restraint ring itself has not been destroyed. At the same time, the interface between the FRP confinement ring with the inner grouting material and the outer concrete has not been cracked and slipping. The experimental phenomena mentioned above show that: (1) the FRP restraint ring can work with the surrounding concrete without the shear slip failure along the interface direction. (2) the FRP restraint ring can bond well with the internal grouting material, and its binding effect on the internal grouting material is obvious.

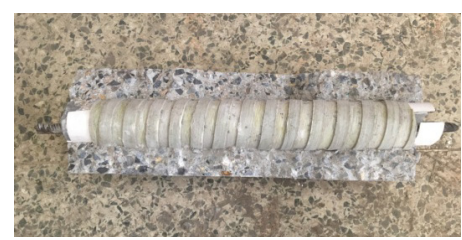

Fig. 5 U3 component

\subsection{Analysis of test results}

Fig. 6 is the stress-strain diagram of the bars obtained under the monotonic tension condition in the test of anchorage length of steel bar in 0.8la. We can see from the graph that the steel bar with diameter of $20 \mathrm{~mm}$ is in elastic state before the strain value is 0.0248 , and the relationship between stress and strain is linear; when strain reaches 0.0248 , the steel bar stress reaches $458 \mathrm{MPa}$. With the increase of strain, the stress growth trend becomes slower, indicating that the steel bar is in the yielding state; When the strain of reinforcing bar reaches 0.1497 , the stress of steel bar reaches $640 \mathrm{MPa}$ and the steel bar of HRB400 is compared to the ultimate strength. This interval is the reinforcing stage of reinforcing bar, and the stress is not increasing; Finally, the sharp decrease of stress indicates that the steel bar is broken. Through the analysis of the stress and strain process of the reinforcement, it is shown that in the process of the test, the reinforcement is a process of over yield, strengthening stage and necking stage, and even finally broken.

According to the monitoring data of the stress and strain state of the steel bar during the test, the reinforcement is broken due to the yield strength until the ultimate strength. The FRP confinement ring is set outside the connection area of the steel bar. In the process of interaction with the micro expansion grouting material, the former plays a certain hoop to the latter, thus the anchorage length of the steel bar can be shortened to a considerable extent. The mechanism is well illustrated by the test process, that 
is, when the anchorage length of the steel bar is reduced by $20 \%$ in the test component, the anchorage performance between the reinforcement and the grouting material for the connection of the component can still be guaranteed.

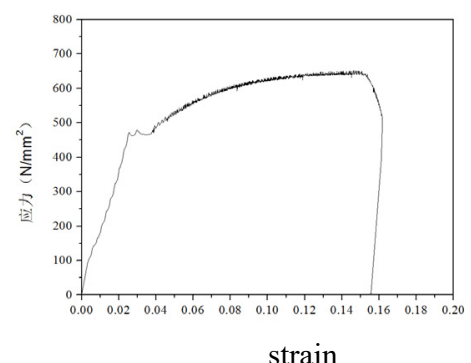

Fig. 6 Stress strain curves of steel bars under monotonic tension

\section{Conclusion}

In this paper, the anchorage tests of 66 groups of specimens show that:

(1) For the FRP restraining ring with different specifications, it can work together with the concrete in the periphery, and can also be well bonded to the internal grouting material, and the binding effect on the internal grouting material is obvious.

( 2 ) The FRP confinement ring produces a certain hoop effect on the micro expansion grouting material, which makes the bond performance of the reinforcing bar greatly improved, so that the anchorage length of the steel bar can be shortened to a considerable extent. For small diameter steel bar $(12 \mathrm{~mm}, 14 \mathrm{~mm}, 16 \mathrm{~mm})$, in the anchorage test of the anchorage length test of 0.8la, it is shown that the ultimate failure mode of the steel bar is broken at the free end of the loading. During the whole loading process, there is no splitting failure in the concrete and the grouting material, the steel bar is pulled out or the bond is broken, and the slip of the steel bar at the free end is zero. Therefore, it can be considered that the anchorage performance between reinforcement and grouting material can be guaranteed.

(3) For the anchorage tests of large-diameter steel bars $(20 \mathrm{~mm}$ and $22 \mathrm{~mm})$ in 0.8la anchorage length, it is shown that the slippage of the reinforcement at the free end is zero. Therefore, it can be considered that the anchorage performance between reinforcement and grouting material can still be guaranteed. According to the test results of anchorage performance, the lap length of reinforcement should be further considered in future lap test.
1. Jiang Hongbin. et al. Journal of Harbin Institute of Technology.45,2(2009)

2. Zhang Haishun. et al. Harbin Institute of Technology.(2009)

3. Zhang Xinghu. et al. Journal of Xi'an University Of Architecture And Technology.45,2(2013)

4. Aizat Alias.et al. edia Engineering. 53,3(2013)

5. Chen Jun. et al. Journal of architectural structure.(2015)

6. Yerlioi V A. et al. ACI Structural Journal.97,3(2000)

7. Englekirk R. Journal of Precast/Prestressed Coneret institute.35,3(1990)

8. Qian Jiaru. et al. Journal of architectural structure.06(2011)

9. Cai Tianran. Xi'an University Of Architecture And Technology.2016

\section{References}

